\title{
ANÁLISE E REDESENHO DE PROCESSOS NO SETOR PÚBLICO: IDENTIFICAÇÃO DE MELHORIAS EM UM PROCESSO DE COMPRA
}

\author{
L. M. BORGES, F. WALTER* e L. C. SANTOS
Universidade Federal da Paraíba (UFPB)
walter@ccsa.ufpb.br* \\ Artigo submetido em novembro/2015 e aceito em janeiro/2016 \\ DOI: $10.15628 /$ holos .2016 .3734
}

\section{RESUMO}

O objetivo deste trabalho é identificar possíveis melhorias no processo de compra de bens na modalidade pregão presencial com registro de preço do Tribunal Regional Eleitoral do Estado da Paraíba (TRE-PB), a partir do seu mapeamento. Para tanto, utilizou como meio de investigação a pesquisa bibliográfica, a análise documental e o estudo de caso. Como técnicas de coleta de dados, utilizou-se a entrevista focalizada aplicada na seção de compras, na comissão permanente de licitação e na seção de programação orçamentária e financeira, e a observação simples através do acompanhamento do fluxo desse processo de compra pelo SADP, programa interno com dados relevantes sobre todos os processos da organização. Como resul ta do, conclui-se que o processo a nalisado é marcado por entraves burocráticos que dificultamo fluxo devido à excessiva e desnecessária concentração de atividades nas coordenadorias e secretarias superiores, provocando um gasto de tempo el evado que poderia ser evita do caso a organização a dotasse suges tões de mel horias propostas neste trabalho.

PALAVRAS-CHAVE: melhoria de processos, gestão de compras, setor público.

\section{PROCESS ANALYSIS AND REDESIGN IN THE PUBLIC SECTOR: IDENTIFICATION OF IMPROVEMENTS IN A PROCUREMENT PROCESS}

\begin{abstract}
This study aims to identify potential improvements in a procurement process of the Tribunal Regional Eleitoral do Estado da Paraíba (TRE-PB), from its process mapping. In order to reach this goal, literature review, document analysis and case study were used, as research approaches. As techniques of data collection, the focused interview was applied at the procurement section, the bidding permanent committee and the budget and financial programming section. Moreover, the simple observation by monitoring the flow of the procurement process
\end{abstract}

from SADP, which is an internal sys tem containing the relevant data about all organizational processes. The results showed that the analyzed process is marked by bureaucratic barriers that hinder the process flow due to excessive and unnecessary concentration of activities in the higher-level departments, causing a huge time expense that could be avoided if the organization adopt suggestions for improvements proposed in this paper

KEYWORDS: process improvement, procurement management, public sector. 


\section{INTRODUÇÃO}

Nos últimos anos o gerenciamento de processos de negócio (BPM - Business Process Management) tem se consolidado como uma importante área do conhecimento no meio acadêmico e uma prática cada vez mais comum no meio empresarial. A orientação gerencial para os processos de negócio foi inicialmente impulsionada pelo movimento da qualidade total e reforçada pelo movimento da reengenharia nas décadas de 1980 e 1990. Posteriormente, o BPM ganhou força com a evolução da tecnologia da informação que, ao passo que abria a possibilidade de as empresas integrarem seus sistemas de informação, requeria a análise e o redesenho de processos como prérequisito para o funcionamento eficiente de sistemas integrados.

Essa evolução fez que o BPM se popularizasse e fosse aplicado em diferentes organizações de diversos segmentos. Embora o nome "negócio" remeta a um pensamento em empresas privadas, as publicações da área mostram que o BPM tem sido aplicado com sucesso no setor público (WAAL; BATENBURG, 2014; HUGHES; SCOTT; GOLDEN, 2006; MACINTOSH, 2003). Autores como Gulledge Jr. e Sommer (2002) e Zwicker, Fettke e Loos (2010) não só confirmam a aplicabilidade como também defendem o BPM como um instrumento de modernização da administração pública para a melhoria dos serviços prestados à população.

Uma característica marcante dos processos organizacionais na administração pública é que o funcionamento dos mesmos geralmente é regido pela legislação vigente e está sujeito à auditoria dos órgãos de fiscalização. Embora essa característica restrinja o potencial de redesenho de processos, ela ressalta a necessidade de padronização de procedimentos, as pecto que pode se beneficiar com a implantação do BPM.

Como acontece em qualquer empresa privada, uma organização do setor público também necessita de processos de suporte para apoiar suas atividades fins. Um exemplo típico de processo de suporte é o processo de compra. De acordo com Viana (2000), a área de compras tem como finalidade suprir a organização com materiais e serviços no tempo, na quantidade, na qualidade e no preço correto, de forma a garantir o seu pleno funcionamento. O processo de compra, de sde a sua solicitação até o recebimento efetivo do material, passa por diversos estágios que envolvem a tomada de importantes decisões, tais como, definir onde e quando comprar, em que quantidade, com quais especificações, dentre outras questões.

No que diz respeito ao processo de compra no contexto do setor público, há uma diferença fundamental em relação ao setor privado: a escolha do fornecedor. Enquanto as empresas privadas têm total liberdade em decidir o fornecedor, as organizações públicas precisam a trelar esta decisão às leis e às normas de licitação pública. Somente este aspecto traz uma série de implicações que tornam o processo de compra no setor público consideravelmente diferente do processo de compra no setor privado. Essa diferença tem gerado um volume expressivo de pesquisas que abordam as peculiaridades das compras no setor público como uma premissa para contribuições científicas relevantes (por exemplo: BERGMAN; LUNDBERG, 2013; EDQUIST; ZABALA-ITURRIAGAGOITIA, 2012; TADELIS, 2012).

Contribuindo para o estudo do tema, o principal objetivo deste artigo é analisar o processo de compra de bens do Tribunal Regional Eleitoral do Estado da Paraíba (TRE-PB), enfocando a modalidade pregão presencial com registro de preços. A partir dessa análise, pretende-se identificar 
possíveis melhorias que proporcionem um processo mais eficiente, contribuindo para uma gestão de materiais adequada às necessidades da organização. Convém destacar que a área de compras do TRE-PB também é responsável pelas compras das demais zonas eleitorais do Estado da Paraíba, constituindo um total de 77 zonas. Do momento em que a compra é solicitada até o recebimento dos materiais ou serviços, forma-se um processo longo e dispendioso envolvendo diversos setores.

Atualmente, a área de compras do TRE-PB cumpre as determinações da Lei $n^{\circ}$ 8.666/93, assim como as suas alterações, ou seja, "contrata periodicamente as compras de: produtos, materiais, serviços e equipamentos necessários à manutenção de suas atividades (...)" (BRASIL, 2015). Assim, o TRE-PB realiza as compras por meio da dispensa de licitação e das modalidades: convite, tomada de preço e pregão presencial. Este último é realizado com registro de preço e sem registro de preço. Considerando que o pregão presencial é a modalidade de licitação mais praticada, meIhorias neste processo tornam-se relevantes.

O texto deste artigo se inicia com esta introdução, seguida de uma breve discussão teórica sobre os conceitos que deram base para o desenvolvimento da pesquisa. Posteriormente, são relatados os procedimentos metodológicos que guiaram a coleta e a análise dos dados necessários para a realização do trabalho. A seção seguinte apresenta a análise do processo e as proposições de melhoria para os problemas identificados. $O$ artigo é encerrado com a discussão de resultados e as considerações finais sobre o trabalho realizado.

\section{FUNDAMENTAÇÃO TEÓRICA}

\subsection{Gerenciamento de processos}

Para Davenport $(1994$, p. 7), processo é "uma ordenação específica das atividades de trabalho no tempo e no espaço, com um começo, um fim, e inputs e outputs claramente identificados: estrutura para a ação". Hammer (1997) destaca a função dos processos como um elemento de agregação de valor que ocorre pela transformação de entradas em saídas. A Associação de Profissionais de Gerenciamento de Processos de Negócio complementa em sua definição que as atividades de um processo são inter-relacionadas e que trabalham juntas para criar um produto final (ABPMP, 2013).

As inter-relações entre as atividades evidenciam duas características comumente associadas ao conceito de processo (ABPMP, 2013; PAIM et al., 2009): as relações cliente-fornecedor e o cruzamento entre fronteiras organizacionais. Um processo de compra, por exemplo, pode envolver uma solicitação de aprovação de crédito proveniente do departamento de compras e direcionada para o departamento de finanças. Somente nesta interação é possível identificar que o processo flui entre pelo menos duas áreas funcionais que se relacionam como cliente interno e fornecedor interno.

Outro aspecto que ajuda a compreender a abrangência do conceito de processo é o reconhecimento de que existem diferentes tipos de processo e que sua operacionalização varia de acordo com a sua finalidade. Para definir as contingências relacionadas ao conceito, alguns autores têm procurado estabelecer modelos de classificação para os processos organizacionais (AITKEN; 
STEPHENSON; BRINKWORTH, 2010; GARVIN, 1998; ARMISTEAD; MACHIN, 1997). Dentre as diferentes propostas, destaca-se a tipologia de Armistead e Machin (1997), que agrupa os processos de negócio em quatro categorias distintas:

- Processos operacionais: são responsáveis pelo trabalho de produzir bens e serviços.

- Processos de suporte: fornecem apoio aos processos operacionais.

- Processos de direcionamento: estão relacionados com o estabelecimento da estratégia da organização.

- Processos gerenciais: envolvem as atividades de tomada de decisão e comunicação na empresa.

A definição da categoria do processo ajuda a definir prioridades na implantação do BPM. Armistead e Machin (1997) observaram que as organizações que adotaram o BPM iniciaram a implantação pelos processos operacionais, seguindo com os processos de suporte e continuando com os processos de direcionamento, de modo que a melhoria em uma categoria pudesse servir de base para a melhoria na categoria seguinte.

A melhoria de processos pode ser vista como um dos elementos do BPM. O propósito fundamental do BPM é fazer com que a organização possa visualizar seu trabalho como um conjunto de processos, de forma a orientar a administração de seu negócio pelo gerenciamento de processos (ABPMP, 2013). As organizações podem ter diferentes objetivos ao adotar uma abordagem orientada por processos, seja para implantar um sistema integrado de informação ou para reprojetar sua estrutura organizacional. Independente do objetivo, a adoção prévia de uma metodologia de melhoria de processos geralmente é necessária à implantação e à manutenção do BPM, uma vez que o gerenciamento de processos pressupõe que os mesmos já foram projetados para funcionar com eficiência e eficácia.

No entanto, a lógica de melhoria de processos não está exclusivamente ligada ao BPM. Diante disso, é possível encontrar na literatura diversas metodologias de melhoria de processos que, mesmo com outras finalidades, podem ser de grande utilidade para o BPM. É caso da estrutura DMAIC (Define, Measure, Analyze, Improve, Control), associada ao programa Seis Sigma de gestão da qualidade (SCHROEDER et al., 2008), e da metodologia de mapeamento do fluxo de valor (ROTHER; SHOOK, 2003), vinculada à implantação de sistemas de produção enxuta.

Por outro lado, o estabelecimento do BPM como área do conhecimento fez surgir nesse contexto um número expressivo de metodologias estruturadas para a melhoria de processos, tais como o framework SAM de Siha e Saad (2008), o modelo WABPI de Coskun, Basligil e Baracli (2008), a metodologia MIPI de Adesola e Baines (2005), a metodologia SUPER de Lee e Chuah (2001), além da metodologia de Povey (1998) e o framework Rohleder e Silver (1997). Enquanto essas metodologias são de propósito genérico, outras metodologias apresentam um escopo mais restrito, como a metodologia desenvolvida por Palma-Mendoza, Neailey e Roy (2014), que se propõe à integração de cadeias de suprimentos, a abordagem HY-CHANGE de Dassisti (2010), mais focada em processos de manufatura, o framework de Khan, Bali e Wickramasinghe (2007), focado em pequenas empresas, ou a metodologia de McAdam (1996), desenvolvida no contexto de um programa de qualidade total.

Usualmente, as metodologias de melhoria de processos seguem a lógica do ciclo contínuo de gerenciamento do BPM, caracterizado pela ABPMP (2013) por seis fases típicas: planejamento, 
análise, desenho, implementação, monitoramento e controle, e refinamento. Essas fases acontecem de forma cíclica, sendo que o refinamento dos processos encerra o ciclo, mas alimenta a próxima fase de planejamento. O Quadro 1 apresenta os objetivos que definem cada uma das fases do BPM e avalia, para cada fase, a abrangência de abordagem de dez metodologias de melhoria de processos que foram revisadas na literatura. Embora alguns dos artigos revisados adotem outras nomenclaturas (framework, por exemplo), considerou-se que o termo "metodologia" é adequado para esta análise, dado que todos os trabalhos pesquisados estabelecem um roteiro estruturado para a melhoria de processos.

Quadro 1 - Fases do BPM e metodologias de melhoria de processos.

\begin{tabular}{|c|c|c|c|c|c|c|c|c|c|c|c|}
\hline \multirow{2}{*}{ Fases do BPM } & \multirow{2}{*}{ Objetivos } & \multicolumn{10}{|c|}{ Metodologias de melhoria de processos } \\
\hline & & 1 & 2 & 3 & 4 & 5 & 6 & 7 & 8 & 9 & 10 \\
\hline Planejamento & $\begin{array}{l}\text { Entender e desenvolver estratégias organi- } \\
\text { zacionais alinhadas com os processos de } \\
\text { negócio. Definir papéis, responsabilidades, } \\
\text { metas e medidas de desempenho. }\end{array}$ & $\mathbf{0}$ & $\mathbf{0}$ & $\mathbf{0}$ & $\mathbf{0}$ & 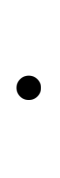 & $\mathbf{0}$ & $\otimes$ & $\mathbf{0}$ & $\mathbf{0}$ & ○ \\
\hline Análise & $\begin{array}{l}\text { Compreender as atividades dos processos } \\
\text { e sua capacidade de atingir as metas defi- } \\
\text { nidas. Identificar restrições e rupturas que } \\
\text { interferem no desempenho dos processos. }\end{array}$ & ○ & O & 0 & 0 & 0 & $\mathbf{0}$ & $\mathbf{0}$ & 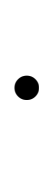 & ○ & 0 \\
\hline Desenho & $\begin{array}{l}\text { Definir o modo que os processos devem } \\
\text { funcionar, seja pela criação de novos pro- } \\
\text { cessos ou pela modificação dos processos } \\
\text { atuais. }\end{array}$ & ○ & O & O & $\mathbf{0}$ & 0 & $\mathbf{0}$ & $\mathbf{0}$ & $\mathbf{0}$ & $\mathbf{0}$ & ○ \\
\hline Implementação & $\begin{array}{l}\text { Colocar em prática os processos desenha- } \\
\text { dos, realizando um novo fluxo de trabalho } \\
\text { e adaptando as ações dos envolvidos às no- } \\
\text { vas formas de agir. }\end{array}$ & ○ & 0 & 0 & O & 0 & 0 & $\mathbf{0}$ & $\mathbf{0}$ & 0 & 0 \\
\hline $\begin{array}{l}\text { Monitoramento } \\
\text { e Controle }\end{array}$ & $\begin{array}{l}\text { Provir informações sobre o des empenho } \\
\text { dos processos em relação ao cumprimento } \\
\text { das metas, à agregação de valor e ao ajuste } \\
\text { dos recursos aos processos. }\end{array}$ & $\mathbf{0}$ & 0 & 0 & 0 & 0 & $\mathbf{0}$ & $\mathbf{0}$ & 0 & 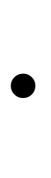 & $\mathbf{0}$ \\
\hline Refinamento & $\begin{array}{l}\text { Ajustar processos após a implementação e } \\
\text { o feedback gerado pelo monitoramento e } \\
\text { controle. Manter o ciclo de melhoria contí- } \\
\text { nua, retornando às fases anteriores. }\end{array}$ & $\otimes$ & 0 & 0 & 0 & 0 & $\mathbf{0}$ & $\mathbf{0}$ & $\mathbf{0}$ & $\otimes$ & $\otimes$ \\
\hline & Aborda completamente & rcia & & & & Nãc & abo & & & & \\
\hline
\end{tabular}

Fonte: Elaborado pelos autores.

No núcleo da melhoria de processos, implícita ao BPM, estão as fases de Análise e Desenho. Todas as metodologias revisadas no Quadro 1 abordaram, ao menos parcialmente, essas duas fases. Enquanto a fase de Análise se preocupa em entender como os processos atuais funcionam, a fase de Desenho se propõe a melhorar a forma atual que os processos operam. A transição para a fase de Desenho é o que caracteriza a melhoria, pois é a partir dessa etapa que as proposições de melhoria começam a aparecer, muitas vezes por meio de uma mudança significativa nos processos. É por esse motivo que a fase de Desenho também é comumente denominada de Redesenho. 
Em ambas as fases, Análise e Desenho, é necessário um trabalho de modelagem de processos. De acordo com Pidd (2003), um modelo pode ser definido como uma representação que descreve parte da realidade, sendo que as pessoas que a descrevem têm o objetivo de entender, mudar, gerenciar ou controlar esta realidade. Logo, a modelagem envolve a criação de modelos, que no caso do BPM pode se referir a processos existentes ou futuros. A fase de Análise gera modelos do tipo "AS-IS", que mostram o estado atual dos processos, ao passo que a fase de Desenho gera modelos do tipo "TO-BE", que mostram o estado futuro que se deseja para os processos (ABPMP, 2013).

A modelagem de processos pode ser realizada de várias formas, utilizando várias técnicas diferentes, a depender da finalidade da modelagem. Aguilar-Savén (2004) realizou uma ampla revisão de literatura e identificou um conjunto abrangente de técnicas de modelagem, desde técnicas mais simples como os fluxogramas, até técnicas mais sofisticadas como redes de Petri e UML (Unified Modelling Language). No entanto, a autora deixa claro que a escolha da técnica não depende de seu grau de sofisticação, mas sim do propósito do modelo e de seu grau de permissividade para mudança. Com base nessas duas dimensões, Aguilar-Savén (2004) propôs um framework para a classificação de técnicas de modelagem de processos que ajuda na seleção da técnica mais adequada para cada caso.

A modelagem completa dos processos envolve a coleta de diferentes informações, incluindo tempos de execução, recursos envolvidos, pessoas responsáveis, dentre outras informações que vão constituir os modelos dos processos (ABPMP, 2013). Porém, uma parte essencial de qualquer modelo de processo é o "mapa do processo". O mapa do processo representa o fluxo de trabalho por meio de sua sequência de atividades e da relação entre elas.

Para auxiliar na elaboração do mapa do processo, Brandon e Morris (1994) propõem a ferramenta MAP (Mapeamento das Atividades Processuais), que funciona como um guia para a descrição abrangente do processo, fazendo uso da representação gráfica do fluxo de trabalho e também das informações detalhadas que estão associadas. A ferramenta MAP destaca a importância de reunir todos os elementos que envolvem a atividade, de forma a se obter mapas de processo mais próximos da realidade. O Quadro 2 fornece uma espécie de checklist para identificar as informações que devem ser incluídas no MAP.

Quadro 2 - Informações que devem ser incluídas no MAP.

1. Informa ção de todas as tel as de sistemas computadorizados que a função organizacional utiliza.

2. Informa ção de todos os relatórios que a função organizacional utiliza, tanto os que sãogera dos por computador como os derivados manualmente.

3. As normas e políticas que regem ca da função organizacional.

4. Qual quer suporte de proces samento externo à organiza ção, ou seja, departamentos de crédito e outros.

5. Informa ções sobre ciclos, como períodos de al ta nas vendas, produção ou processamento.

6. Detalhes sobre quem, o que, quando, onde, como e por quê.
7. Qualquer atividade especial, por exemplo, projetos em que o pessoal a propriado estej a envolvido.

8. Informa ções por volume, tota lizadas por período e totalizadas por pessoa, de a cordo coma classificação e nível de emprego.

9. Detalhamento de posições do pessoal ea quantidade de funcionários por descrição de posiçãoe grau de habilidade.

10. Reconhecimento básico de todas as tarefas relevantes executadas em uma função organizacional e a classificação das mesmas em seus trabalhos.

11. Identificação de fal has do atual método de trabalho pel o qual a função organizacional está sendo executada.

Fonte: Adaptado de Brandon e Morris (1994, p. 139).

A simples análise do mapa do processo geralmente é suficiente para propor melhorias. 
Nesse sentido, Mischak (1997) sugere, esquematizando na Figura 1, um conjunto de procedimentos para a melhoria de processos que podem ser feitos a partir da análise dos mapas dos processos. Os procedimentos propostos por Mischak (1997) são particularmente úteis para guiar o redesenho dos processos atuais, a partir da análise e da identificação de restrições e oportunidades de meIhoria para a operação dos mesmos.

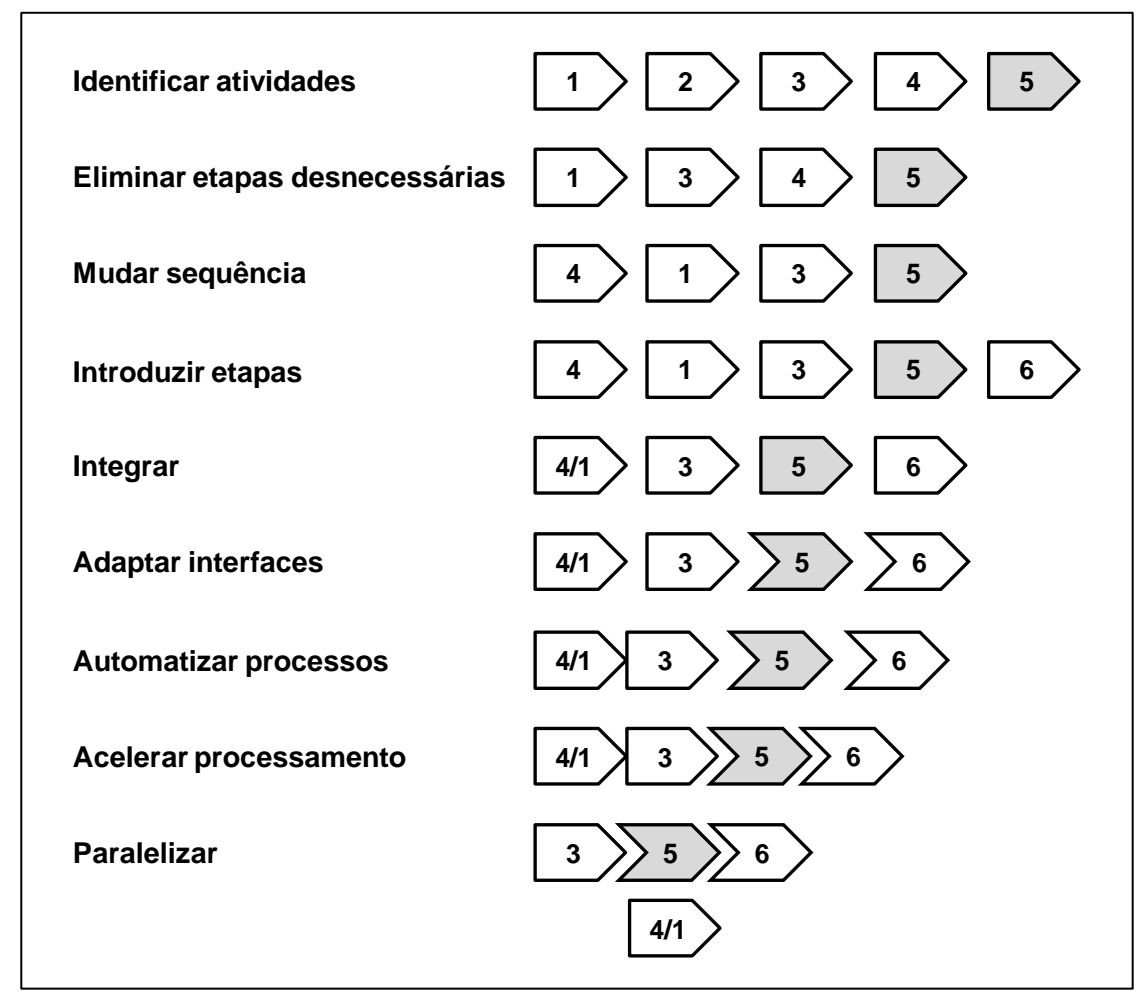

Figura 1 - Procedimentos para a melhoria de processos. Fonte: Mischak (1997).

Ao analisar um processo é necessário conhecer as peculiaridades e as restrições inerentes ao processo analisado. Esses aspectos são de fundamental importância para se definir alternativas de redesenho viáveis e compatíveis com a realidade da organização estudada. De acordo com o objetivo deste trabalho, é importante revisar algumas características do processo de compras na Administração Pública.

\subsection{Compras na Administração Pública}

Segundo Fernandes (2009, p. 43), a "administração de material destina-se a dotar a administração dos meios necessários ao suprimento de materiais imprescindíveis ao funcionamento da organização, no tempo oportuno, na quantidade necessária, na qualidade requerida e pelos menores custos". No que diz respeito às funções que compõem a Administração de Materiais, Dias (2011) define a sua organização tradicional da seguinte forma: controle de estoques, compras, almoxarifado, planejamento e controle da produção, importação, transporte e distribuição. De forma geral, a função Compras é responsável por fazer com que a organização receba os suprimentos dentro dos critérios especificados e é responsável por buscar fora da organização e nas melhores condições, os materiais necessários para o seu funcionamento.

A Administração Pública diz respeito aos agentes públicos, os órgãos e as funções desempenhadas por eles. Tem como foco o bem-estar coletivo, sendo de sua responsabilidade reunir 
esforços para atender as necessidades de direito dos cidadãos. As ações públicas devem estar em conformidade com os princípios básicos previstos na constituição brasileira, que em seu artigo 37 determina: "A administração pública direta e indireta de qualquer dos Poderes da União, dos Estados, do Distrito Federal e dos Municípios obedecerá aos princípios de legalidade, impessoalidade, moralidade, publicidade e eficiência".

Quando se trata de compras na administração pública, estas devem ser realizadas quase sempre através de licitação. Segundo Meirelles (2005), o processo de licitação é composto por duas fases: interna e externa. É na fase interna que a autoridade competente autoriza a abertura do processo, indicando os recursos disponíveis para a realização e as características do objeto licitado. A fase externa é composta pelas seguintes etapas: audiência pública; edital ou convite; recebimento da documentação ou proposta; habilitação dos licitantes; julgamento das propostas e homologação e adjudicação.

Meirelles (2005) apresenta a sequência das etapas que constitui o processo licitatório, sendo que em cada modalidade há algumas diferenças nessa sequência. De acordo com o autor, a etapa "habilitação dos licitantes", no caso da concorrência, ocorre na fase preliminar do julgamento das propostas, enquanto a tomada de preço ocorre anteriormente à abertura da licitação, já que os interessados devem estar inscritos no registro cadastral. Na modalidade convite, o autor considera uma situação a priori, pois a organização convoca aqueles que julga capacitados, o que não impede de exigir comprovantes se considerar necessário. No leilão, a habilitação é desnecessária, sendo que em casos especiais poderá exigi-la, como no caso de leilão dentro do plano nacional de desestatização. Já no caso do pregão, a fase habilitação é invertida, depois do julgamento das propostas se examinará a documentação do vencedor. Por último, no caso do concurso, a habilitação é facultativa.

Comparando-se os processos de compras em organizações privadas e públicas, percebemse diferenças, porém a ideia central do fluxo de compra é a mesma. Nas duas situações a fase inicial consiste na preparação do processo, definindo objeto e recursos disponíveis para a compra. No segundo momento, inicia-se a busca pelo fornecedor que melhor atenda aos critérios estipulados. Depois de avaliar as propostas e escolher a mais vantajosa, realiza-se o contrato entre as partes, finalizando o processo com o recebimento da Compra.

O ponto crucial que determina as diferenças nesses processos é a formalidade, exigida por lei, das atividades no âmbito público, contrastando com a informalidade nas organizações privadas: "a diferença fundamental entre tais atividades é a formalidade no serviço público e a informalidade na iniciativa privada, muito embora com procedimentos praticamente idênticos, independentemente dessa particularidade" (VIANA, 2000, p. 176). Enquanto as empresas privadas têm total autonomia para decidir de que fonte a compra será realizada, na administração pública não pode haver qualquer decisão tendenciosa, pois a escolha deste se dá através de um processo licitatório que é regido pela Lei $n^{\circ} 8.666 / 93$. De acordo com Di Pietro (2008, p. 335), o segundo artigo da Lei $n^{\circ}$ 8.666/93 exige licitação para "obras, serviços, inclusive de publicidade, compras alienações, concessões, permissões e locações". Já o artigo primeiro desta mesma Lei determina que "estão obrigados à licitação todos os órgãos da Administração Pública direta, os fundos especiais, as autarquias, as fundações públicas, as empresas públicas, as sociedades de economia mista e demais entidades controladas direta ou indiretamente pela União, Estados, Distrito Federal e Municípios" (DI PIETRO, 2008, p. 343). 
O artigo 22 da Lei $n^{\circ}$ 8.666/93 estabelece cinco modalidades de licitação: concorrência, tomada de preços, convite, concurso e leilão. Há ainda a modalidade pregão, que foi instituída pela Lei $n^{\circ}$ 10.520/2002 e que, segundo Di Pietro (2008, p. 366), destina-se a "aquisição de bens e serviços comuns, qualquer que seja o valor estimado da contratação, em que a dis puta pelo fornecimento é feita por meio de propostas e lances em sessão pública".

Meirelles (2005) completa essa definição afirmando que o pregão pode ser utilizado para adquirir bens e/ou serviços comuns, cujos padrões de desempenho e qualidade são especificados no edital de forma objetiva, utilizando características comumente praticadas no mercado e admitindo apenas a escolha do licitante pelo critério de menor preço.

O pregão pode ocorrer tanto de forma presencial quanto eletrônico. Gasparini (2008, p. 576) afirma que o "pregão presencial é definido pelo art. 2 do Regulamento aprovado pelo Decreto n. 3555/2000 como a modalidade de licitação em que a disputa pelo fornecimento de bens ou serviços comuns é feita em sessão pública, por meio de propostas de preços escritas e lances verbais". Conforme Slomski (2003, apud DONEL et al., 2008, p. 50), "o pregão eletrônico é o ato da disputa pelo fornecimento de bens e serviços comuns realizado em sessão pública, por meio de propostas e lances que acontecem através da rede mundial de comunicação".

A formalidade exigida ao processo de compra na administração pública geralmente implica em aumento da burocracia e lentidão para a execução do orçamento anual. Paradoxalmente, conforme mencionado anteriormente, a Constituição Federal define a "eficiência" com um dos princípios fundamentais da administração pública. É neste aspecto que as metodologias de melhoria de processos podem auxiliar a combater os efeitos indesejados da burocracia, mantendo o cumprimento da legislação vigente, porém, atendendo simultaneamente ao princípio da eficiência.

\section{PROCEDIMENTOS METODOLÓGICOS}

Esta pesquisa se propõe a identificar melhorias em um processo de compra de uma organização pública. Como a pesquisa visa contribuir para a resolução de um problema prático, ela se caracteriza como pesquisa aplicada. Este estudo também pode ser considerado como exploratório e descritivo. Exploratório por buscar uma maior compreensão acerca do que se investiga, permitindo ao pesquisador delimitar de forma mais precisa o problema (ACEVEDO; NOHARA, 2007). Descritivo pelo fato de detalhar as etapas que compõem o processo analisado, descrevendo cada atividade executada e a relação entre elas.

Num primeiro momento foi feita uma pesquisa bibliográfica a fim de conhecer as bases teóricas sobre o tema, assim como o conjunto de ferramentas que poderiam dar suporte à pesquisa de campo. Aproveitando o conhecimento publicado em livros e artigos, pôde-se escolher modelos de mapeamento e melhoria de processos que mais se adequassem à finalidade desta pesquisa.

Utilizando as palavras de Sampieri, Collado e Lucio (2013), a pesquisa de campo exigiu uma "imersão" no objeto de estudo e demandou uma abordagem qualitativa de análise, considerando que essa seria a forma mais viável de se obter as informações necessárias para a realização do 
objetivo de propor melhorias ao processo da organização. Por isso, a pesquisa de campo foi conduzida pelo método do estudo de caso, que segundo Yin (2015), é adequado quando se deseja estudar em profundidade um fenômeno contemporâneo dentro do contexto da vida real.

O estudo foi realizado na área de compras do Tribunal Regional Eleitoral do Estado da Paraíba (TRE-PB). Considerando que existem diferentes modalidades de compra no TRE-PB e cada modalidade é executada por um macroprocesso distinto, esses macroprocessos podem ser considerados como unidades de análise da pesquisa. Depois de se obter uma visão geral dos macroprocessos de compras, foi selecionado o macroprocesso pregão presencial com registro de preço na aquisição de bens para o aprofundamento do estudo. Esse macroprocesso, incluindo seus processos e subprocessos derivados, representou o objeto principal do estudo de caso.

As principais técnicas de coleta de dados desta pesquisa foram a entrevista focalizada e a observação simples. Na entrevista focalizada o entrevistador estabelece pontos para serem abordados com o entrevistado, de forma a focalizar e aprofundar em apenas um assunto (VERGARA, 2008). Guiada por um roteiro, inicialmente realizou-se uma entrevista com os dois assistentes de pesquisa e cadastro da Seção de Compras (SECOMP), que informaram quais são os processos de Compra adotados pelo TRE-PB e as etapas que compõem cada um. Com essas informações, realizou-se um mapeamento preliminar de cada processo de compra, e a partir desta primeira análise, percebeu-se que a modalidade pregão presencial com registro de preço é a mais praticada e que envolve mais setores na sua execução. Diante disso, optou-se por focar apenas nesta modalidade. Com o mapeamento preliminar desse processo, retornou-se à SECOMP objetivando verificar com os funcionários entrevistados se o que tinha sido mapeado condizia com o praticado. Em seguida, esclareceram-se alguns pontos e, desta forma, guiando-se por um roteiro, foi realizada uma entrevista com o chefe da Seção de Programação Orçamentária e Financeira (SEPOF), que explicou detalhadamente o caminho percorrido pelo processo em toda a Coordenadoria de Orçamento e Finanças (COF). Por último, o pregoeiro da Comissão Permanente de Licitação (CPL) foi entrevistado, também utilizando um roteiro como orientação, com a finalidade de detalhar a fase externa do pregão, ou seja, desde a elaboração do edital à escolha do vencedor.

O macroprocesso escolhido para a análise demonstra um comportamento típico de cruzamento entre fronteiras organizacionais, uma vez vários setores participam do mesmo. Porém, as pessoas da SECOMP, da SEPOF e da CPL foram consideradas suficientes como sujeitos da pesquisa, informando sobre o fluxo dos processos mesmo em setores que eles não faziam parte.

Na observação simples o observador mantém certo distanciamento da situação ou do grupo a ser estudado e não interage com os elementos observados (VERGARA, 2008). Para uma compreensão realística do processo em questão foi importante observar o fluxo desse processo através do SADP (Sistema de Acompanhamento de Documentos e Processos), sistema que informa o percurso dos processos da organização.

Complementando as entrevistas e as observações dos processos, utilizou-se a pesquisa documental. Desse modo, buscou-se em resoluções, portarias, regimentos, atas, ofícios, entre outros documentos da organização, informações relevantes para compreender os procedimentos determinantes dos processos de compra.

A análise de dados abrangeu as fases de "Análise" e "Desenho" (Quadro 1), estabelecidas pela metodologia de referência da ABPMP (2013). Os procedimentos de mapeamento e melhoria 
de processos adotados por este estudo foram a ferramenta MAP, proposta por Brandon e Morris (1994) e os procedimentos de melhoria propostos por Mischak (1997) (Figura 1). O software Dia foi utilizado para criar fluxogramas dos processos, mapeando-os através dos recursos de imagens de processos. O modelo de fluxograma utilizado foi o padrão do American National Standards Institute (ANSI), que permite compreender de forma detalhada o funcionamento de um processo (HARRINGTON, 1993). É importante destacar que fluxograma simples no padrão ANSI atendeu completamente ao propósito desta pesquisa, considerando as recomendações de Aguilar-Savén (2004) para a escolha da técnica de modelagem de processos.

\section{RESULTADOS}

O macroprocesso pregão presencial com registro de preço está dividido em dois processos: "processamento do pregão" (com os subprocessos formalização do pedido de compra, verificação financeira, autorização da licitação e elaboração do edital, escolha do fornecedor e homologação e adjudicação do fornecedor) e "recebimento do objeto licitado" (com os subprocessos solicitação de recebimento e empenho, recebimento do material e pagamento). Por se tratar de registro de preço, o recebimento do material pode ocorrer em parcelas, num período de até um ano, de acordo com a conveniência do setor requisitante.

Após o mapeamento detalhado de cada etapa destes dois processos, ambos foram analisados visando ações de melhoria. As sugestões aqui apresentadas resultam de análises orientadas pelos procedimentos de melhoria esquematizados por Mischak (2008), principalmente no que concerne à eliminação de etapas desnecessárias, mudança de sequência e introdução de etapas.

\subsection{Melhoria do "processamento do pregão"}

Após coletar dados suficientes sobre este processo, o processamento do pregão pôde ser mapeado conforme a Figura 2.

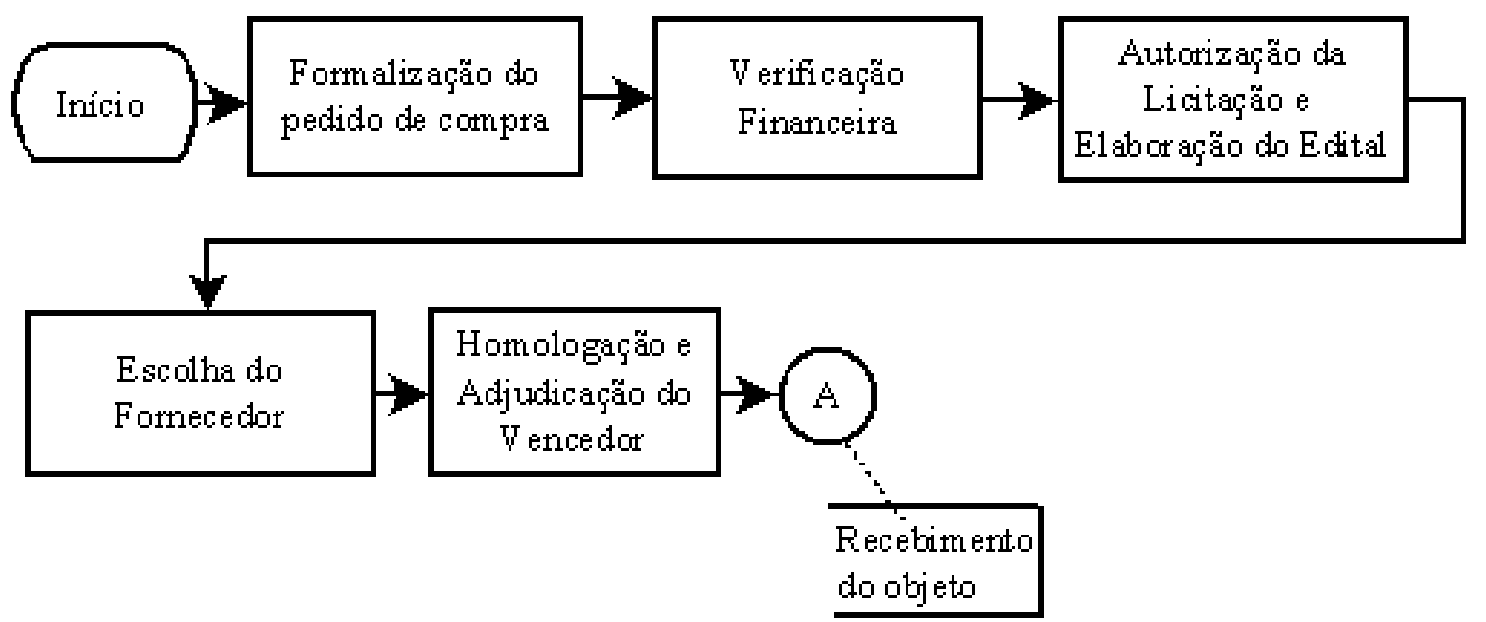

Figura 2 - Processamento do pregão.

Fonte: Elaborada pelos autores.

As proposições de melhoria atuaram nos subprocessos do processamento do pregão e são detalhados a seguir. 
Formalização do pedido de compra: A formalização do pedido consiste em transformar uma solicitação de material (via memorando) em um processo formal (autuar). Após a análise, identificou-se que a atividade 2 é desnecessária e pode ser eliminada.

Além da formalização que a COMAT (Coordenadoria de Material) realiza, é também necessário que o setor de protocolo registre o pedido no Sistema de Acompanhamento de Documentos e Processos - SADP, atividade que poderá ser realizada antes da autuação, já que há informações suficientes para o registro no SADP no memorando de solicitação. Considerando esta possibilidade e sabendo que o subprocesso seguinte inicia-se com a pesquisa de preço a ser realizada pela SECOMP, e sabendo também que esta seção situa-se na sala contígua à COMAT, e que o setor de protocolo localiza-se no térreo do prédio, pode-se inverter as atividades 3 e 4 de forma a agilizar a tramitação pela proximidade física dos setores. A simplificação pode ser observada na Figura 3.

ANTE S

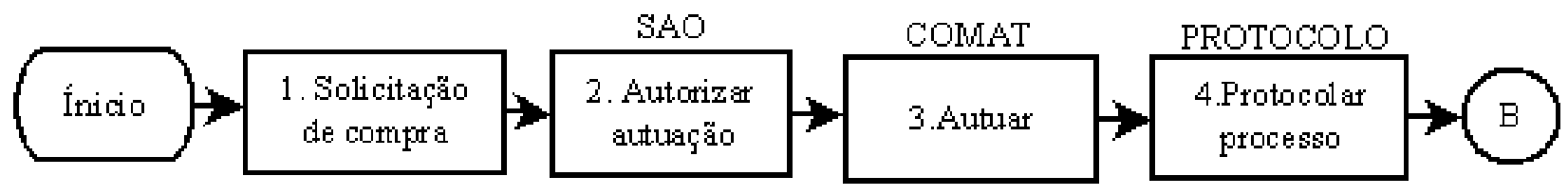

\section{DEPOIS}

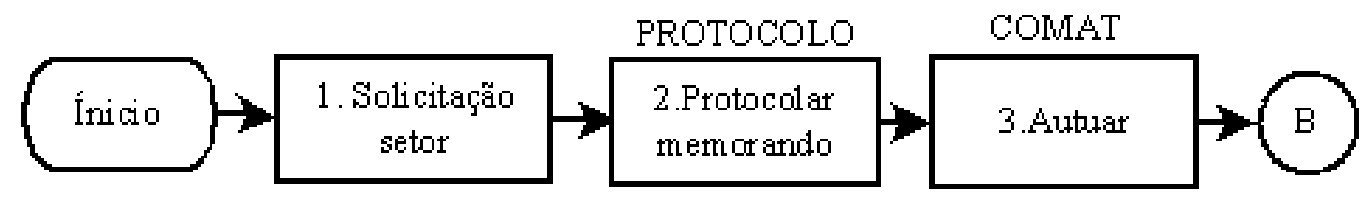

Figura 3 - Formalização do pedido (nova proposta).

Fonte: Elaborada pelos autores.

Verificação financeira: Depois que a pesquisa de preço é realizada pela SECOMP, verifica se se a despesa está prevista no orçamento. No fluxo atual, as atividades 6, 7, 9 e 11 não agregam nenhuma informação, podendo ser eliminadas sem prejuízo da tramitação (Figura 4). A atividade 14, pertencente ao subprocesso seguinte (autorização da licitação e elaboração do edital), consiste no encaminhamento dos autos à Diretoria Geral para autorização da licitação. Esta atividade, executada pela COF, poderia adotar um caráter de conferência do pré-empenho realizado e não se resumir a uma tramitação simples, pois, finalizado este subprocesso, significará que uma reserva preliminar do dinheiro foi efetivada, o que interfere na disponibilidade orçamentária do TRE-PB, exigindo assim um acompanhamento mais próximo da COF. Portanto, a atividade 14, pertencente atualmente ao subprocesso seguinte seria deslocada para o último momento deste subprocesso com uma nova atribuição, ou seja, corresponderia à atividade 9. 

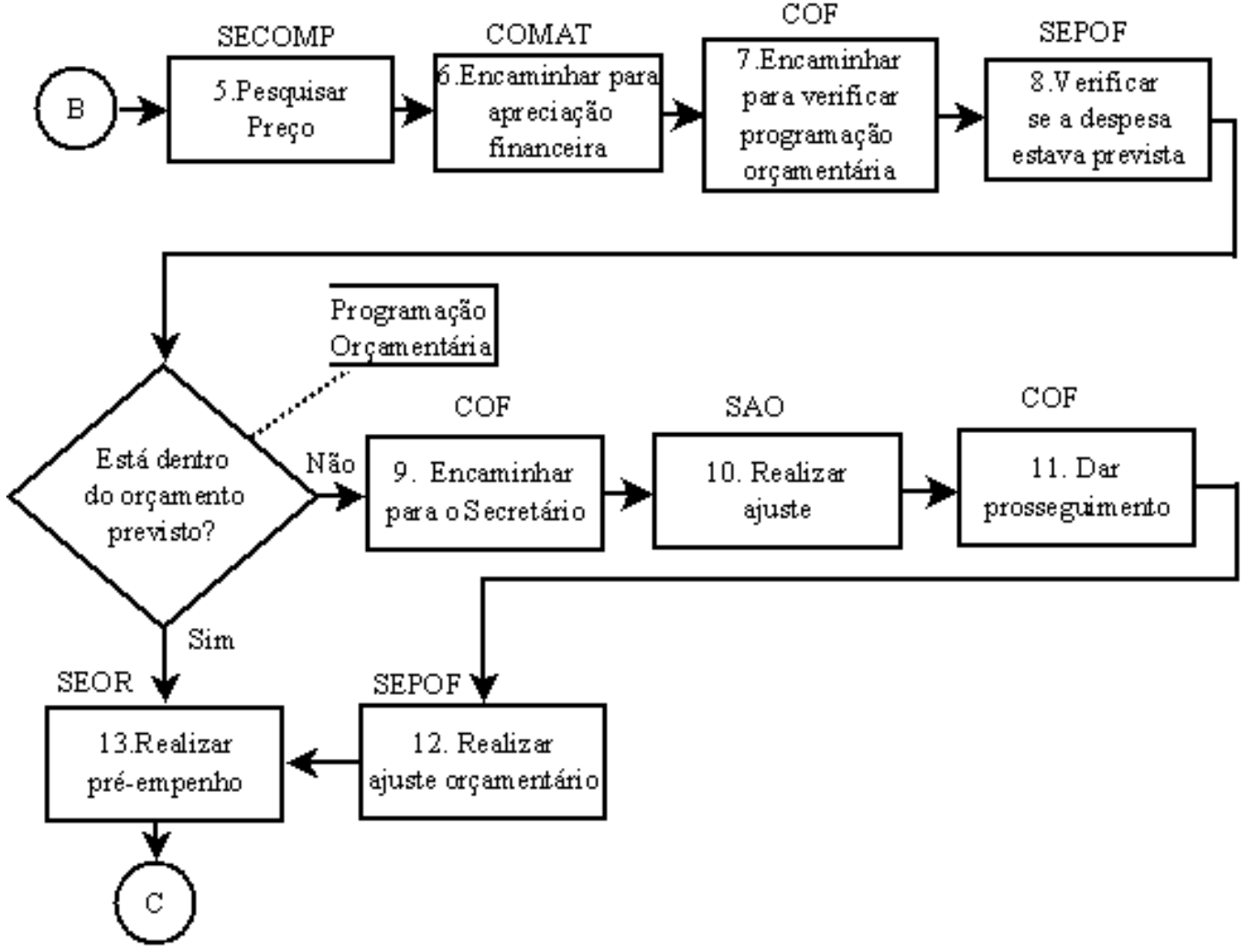

DEPOIS

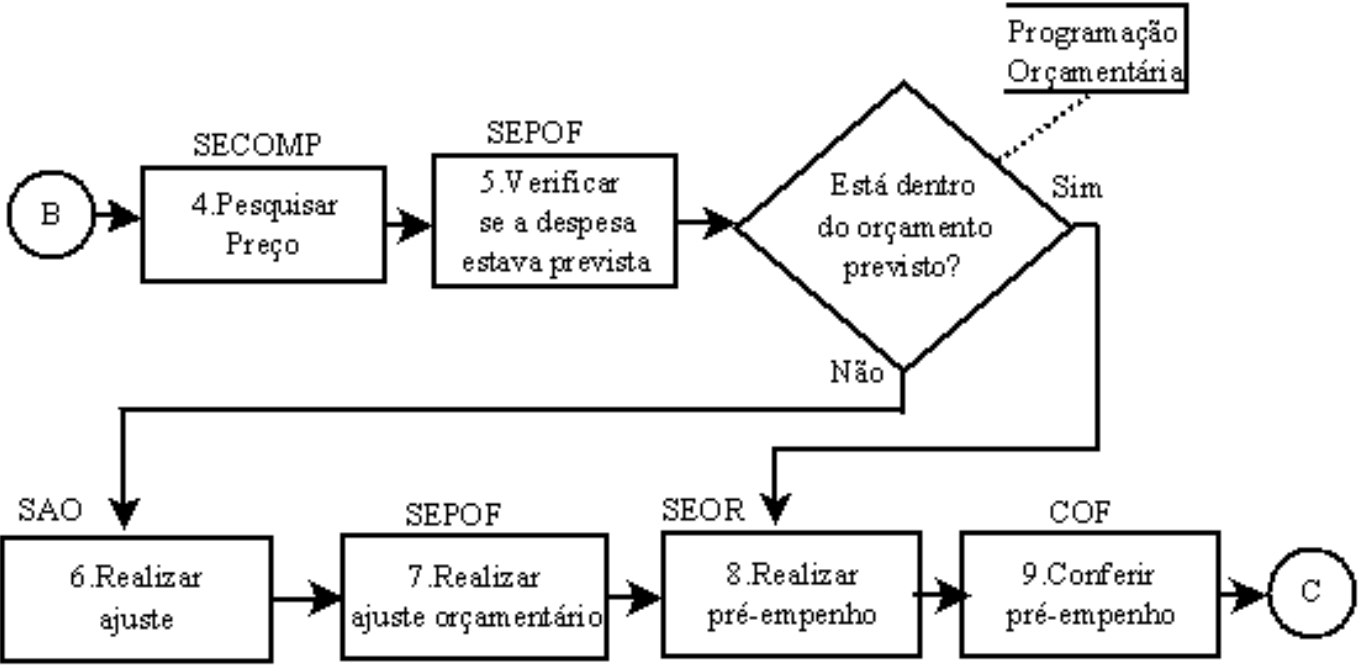

Figura 4 - Verificação financeira (nova proposta).

Fonte: Elaborada pelos autores.

Autorização da licitação e elaboração do edital: Visando eliminar atividades que não agregam informações, pode-se suprimir as atividades 15, 18, 19, 22 e 23, pois consistem em encaminhamentos ou solicitações formalmente praticadas entre setores hierarquicamente superiores, mas que não deliberam, controlam ou orientam a tramitação (Figura 5). 


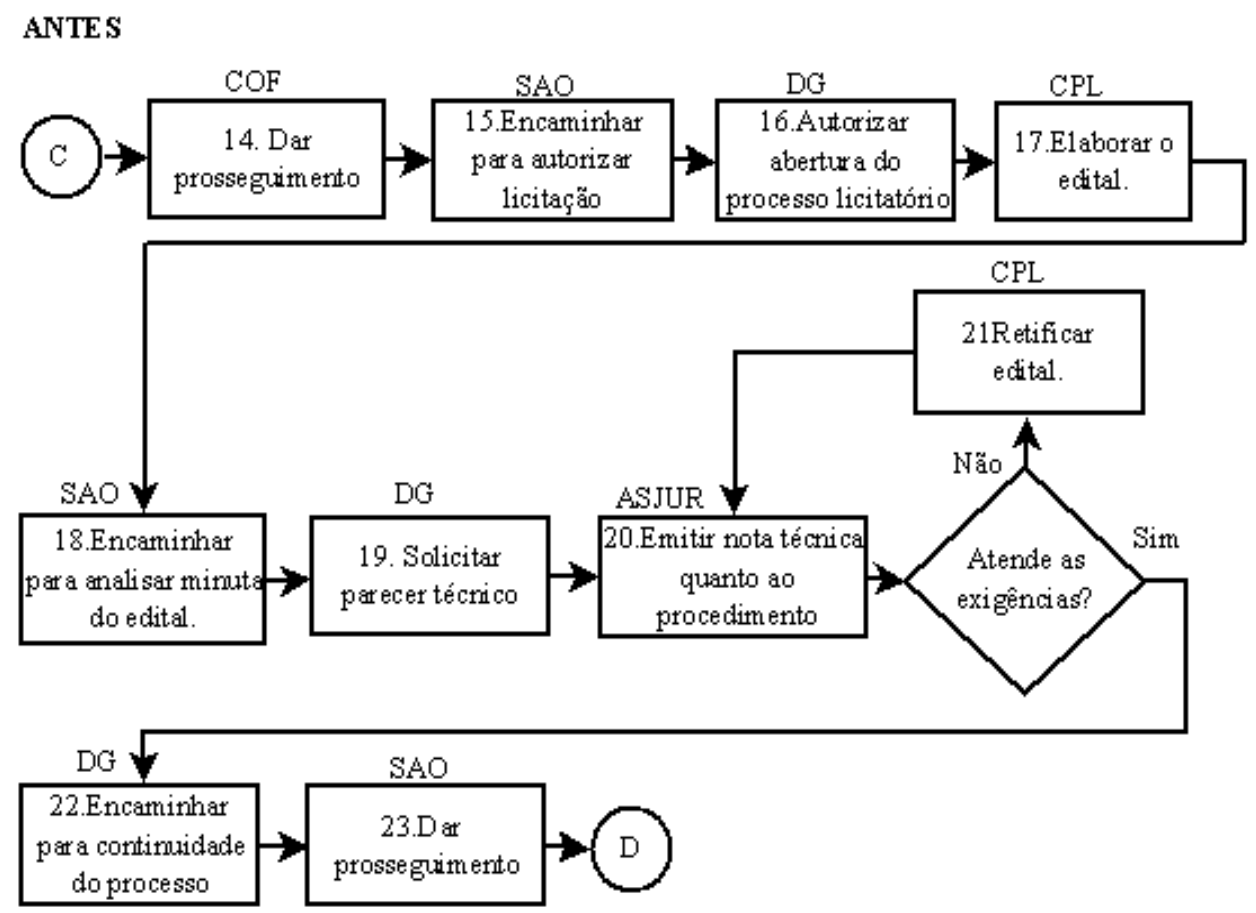

DEPOIS

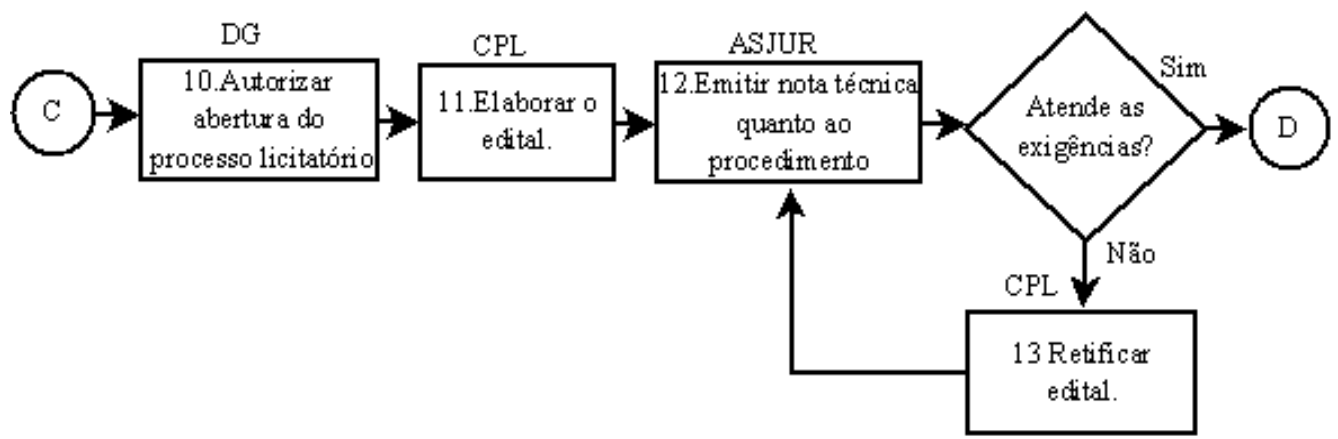

Figura 5 - Autorização da licitação e elaboração do edital (nova proposta).

Fonte: Elaborada pelos autores.

Escolha do fornecedor: Não há nenhuma consideração de melhoria quanto à sequência das atividades que compõem a escolha do fornecedor. A maior parte desse subprocesso, e em sua totalidade quando nenhum licitante interpõe recurso, ocorre num único setor, na CPL.

Homologação e adjudicação do vencedor: Após a escolha da melhor proposta, antes de homologar a decisão pelo vencedor, é necessária uma verificação técnica quanto ao procedimento e à legalidade, atividades que são executadas respectivamente pela ASJUR (Assessoria Jurídica) e $\mathrm{CCl}$ (Coordenadoria de Controle Interno). Já a homologação é realizada pela SAO (Secretaria de Administração e Orçamento). Logo, as atividades 34 e 35 que antecedem a verificação técnica (Figura 6), como também a 38, que antecede a homologação, são dispensáveis, tendo em vista que os setores citados (ASJUR, CCI E SAO) são os responsáveis para a efetiva análise e aprovação da decisão pelo vencedor, não havendo necessidade de intermediação formal de outros. Depois da 
homologação, para concretização da adjudicação, providencia-se a confecção da ata, coleta da assinatura do(s) vencedor(es) e publicação da mesma. Essas atividades são de responsabilidade da SECOMP, o que dispensa a atividade 40 (COMAT encaminha à SECOMP para as providências) por ter apenas a finalidade de intermediar a tramitação entre a SAO e a SECOMP. As atividades 45 e 46, sobrestar processo originário e aguardar pedidos do setor, de responsabilidade da COMAT, poderiam ser realizadas pela SECOMP, já que este é o setor que receberá a solicitação do recebimento do material, próxima etapa considerando a implementação da melhoria do subprocesso "solicitação de recebimento e empenho". Logo, visando agilizar a tramitação, a nova proposta deixaria os autos sobrestados na própria SECOMP.

ANTES

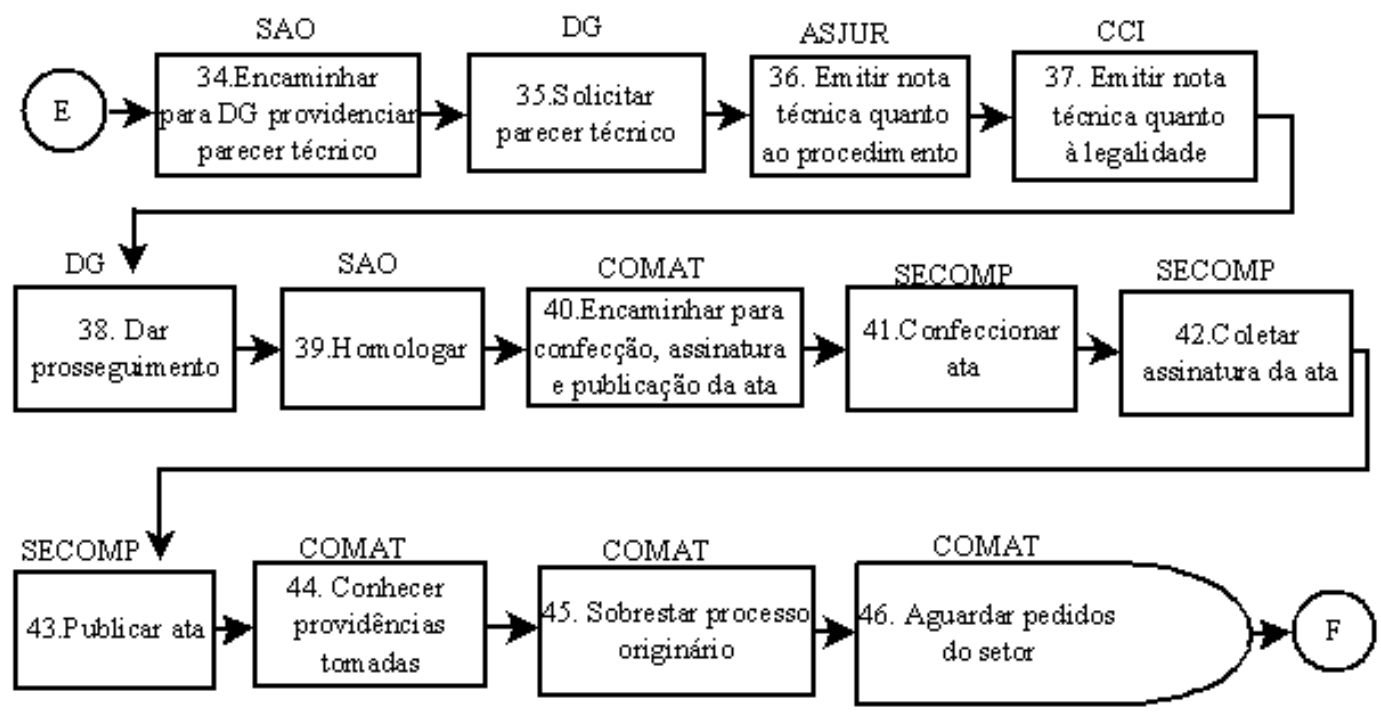

DEPOIS

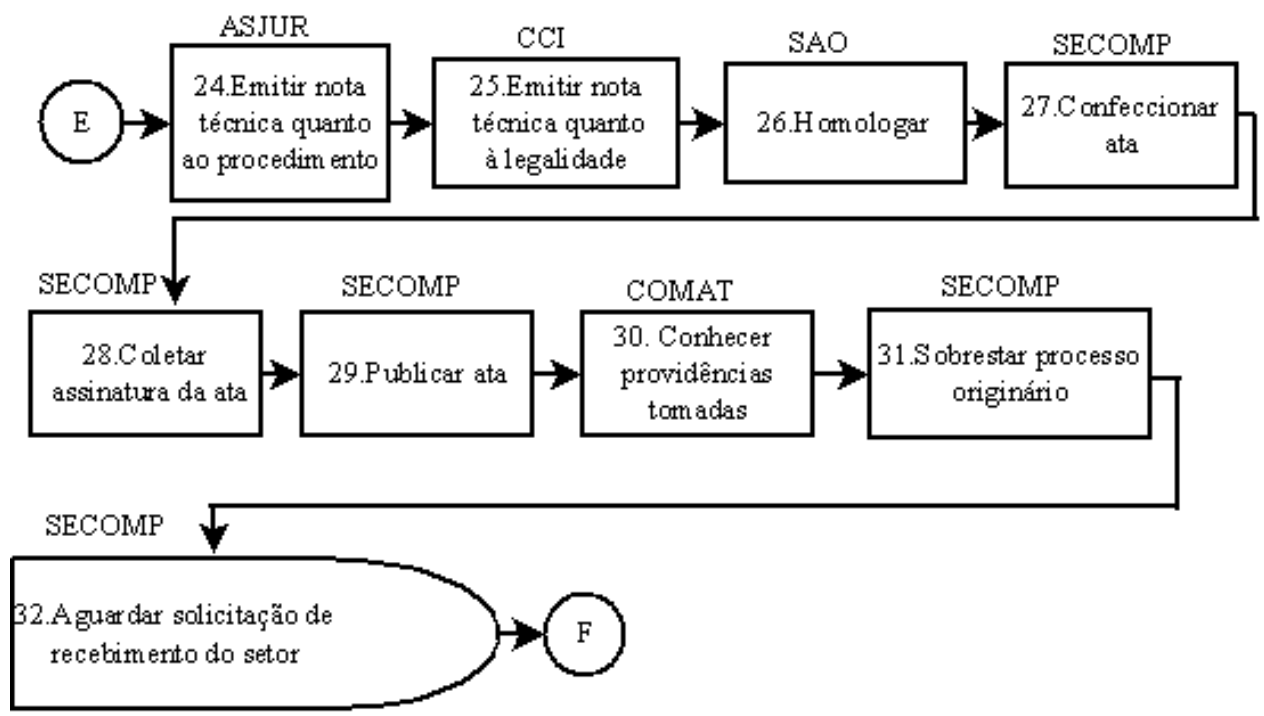

Figura 6 - Homologação e adjudicação do vencedor (nova proposta). Fonte: Elaborada pelos autores. 


\subsection{Melhoria do "recebimento do objeto licitado"}

A Figura 7 apresenta o mapa do processo "recebimento do objeto licitado". A identificação de melhorias nos subprocessos é detalhada a seguir.

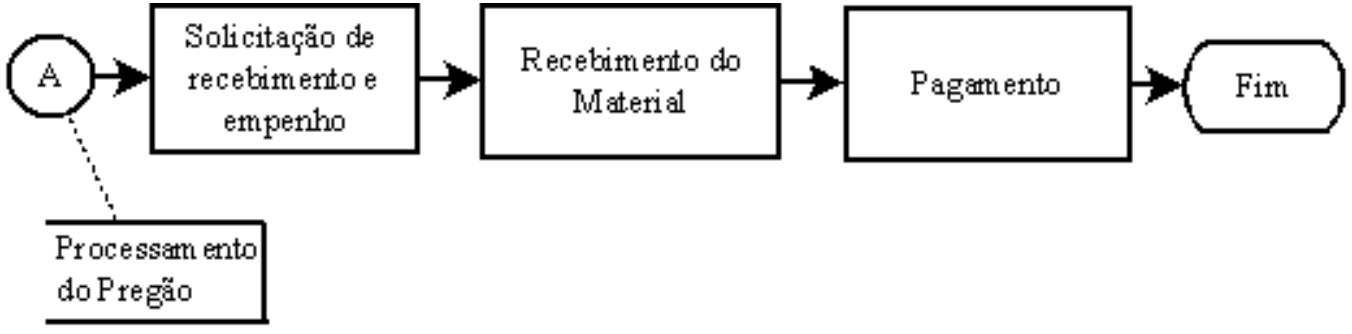

Figura 7 - Recebimento do objeto licitado.

Fonte: Elaborada pelos autores.

Solicitação de recebimento e empenho: O setor que solicitou a compra poderá requisitar o recebimento de uma parte ou da totalidade do objeto licitado. Como a autorização da licitação, a homologação e adjudicação do vencedor foram efetivadas anteriormente, não há necessidade de uma nova autorização para emissão da O.C. (Ordem de Compra), tendo em vista que a compra já tinha sido autorizada e o dinheiro previamente reservado. Portanto, são dispensáveis a atividade 49, e consequentemente a antecedente, que consiste na solicitação da autorização da emissão da ordem (Figura 8). Também é dispensável a intermediação formal para requisitar a nota de empenho (atividades 51 e 52) e para dar continuidade ao processo após a realização da conformidade contábil (atividade 55).

\section{ANTE S}

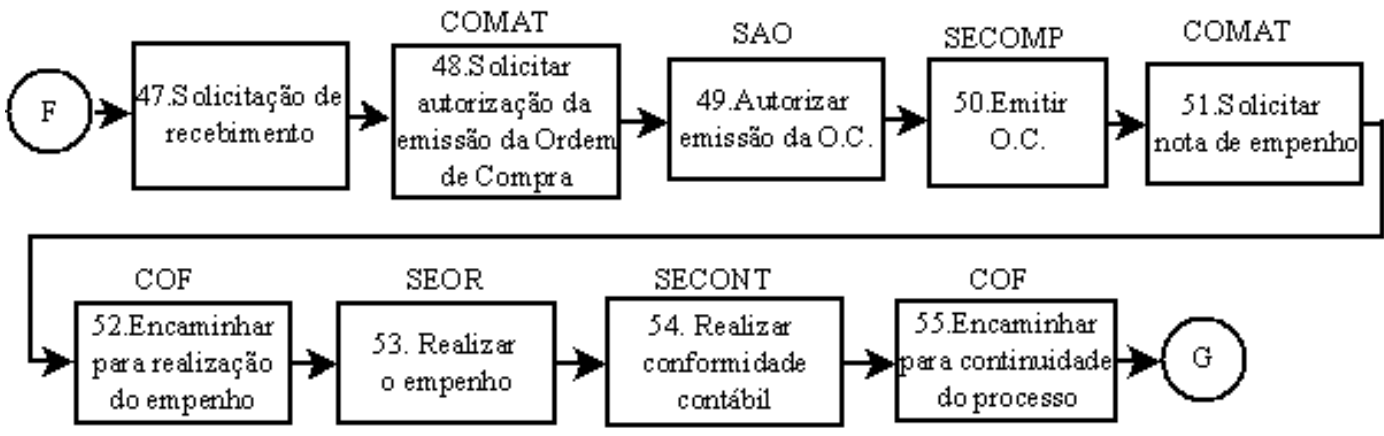

DEPOIS

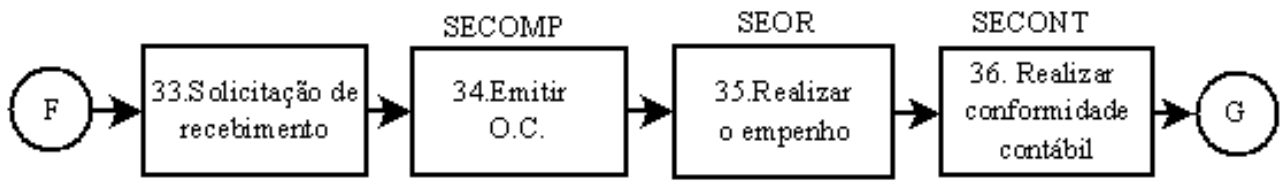

Figura 8 - Solicitação de recebimento e empenho (nova proposta).

Fonte: Elaborada pelos autores. 
Recebimento do material: Não há sugestões de melhoria para as etapas que compõem este subprocesso. Está em conformidade a sequência das atividades, bem como os responsáveis por elas, no caso das quatro, três são executadas pela SEAL (Seção de Almoxarifado).

Pagamento: O pagamento ao fornecedor só ocorre depois que o material é recebido, conferido e apropriado no sistema financeiro. Quem efetiva o pagamento é a SEFIN (Seção de Execução Financeira), portanto é possível o envio direto dos autos a este setor sem prejuízo da tramitação, ficando desta forma dispensadas as atividades 60, 61 e 62 (Figura 9). A atividade 65, também pode ser dispensada, já que não agrega nenhuma informação.
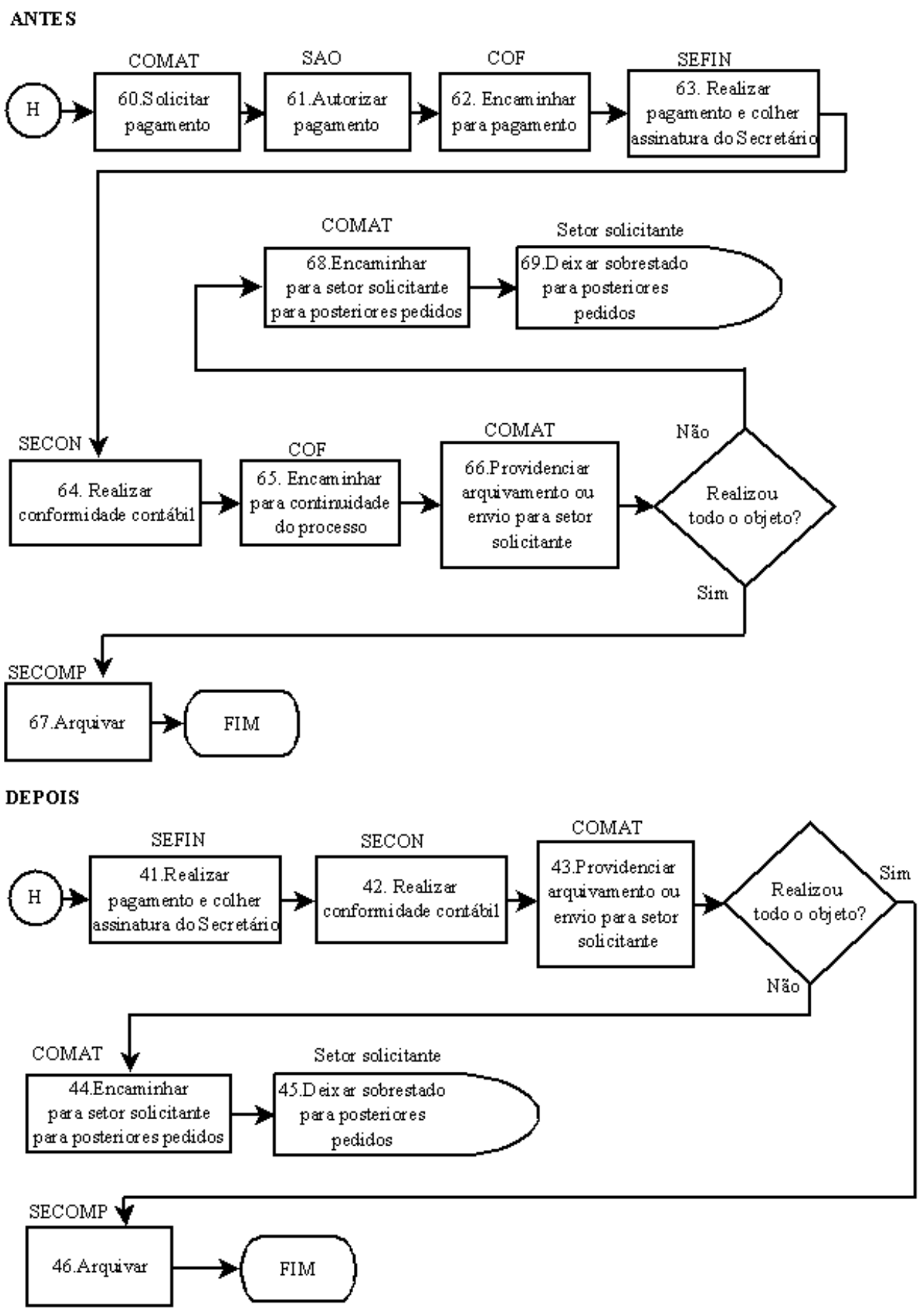

Figura 9 - Pagamento (nova proposta).

Fonte: Elaborada pelos autores. 


\subsection{Discussão}

As melhorias identificadas representam proposições de implementação para a organização estudada. O Quadro 3 sintetiza as melhorias propostas e identifica os procedimentos sugeridos por Mischak (1997) que foram adotados.

Quadro 3 - Síntese das melhorias identificadas.

\begin{tabular}{|c|c|c|c|}
\hline Processo & Subprocesso & Principais melhorias propostas & $\begin{array}{l}\text { Procedimentos de me- } \\
\text { Ihoria adotados }\end{array}$ \\
\hline \multirow{4}{*}{$\begin{array}{l}\text { Processamento } \\
\text { do pregão }\end{array}$} & Formalização do pedido & $\begin{array}{l}\text { - Eliminou-se a ativida de "autorizar au- } \\
\text { tuação". } \\
\text { - "Protocolar memorando" passou a ser } \\
\text { executada antes de "Autuar". }\end{array}$ & $\begin{array}{l}\text { - Eliminar etapas des- } \\
\text { necessárias } \\
\text { - Mudar sequência }\end{array}$ \\
\hline & Verificação financeira & $\begin{array}{l}\text { - As atividades 6, 7,9 e } 11 \text { foram elimi- } \\
\text { nadas. } \\
\text { - A atividade “Conferir pré-empenho" } \\
\text { (pertencente ao anteriormente se- } \\
\text { guinte) foi incorporada e passou a ter } \\
\text { uma nova finalidade. }\end{array}$ & $\begin{array}{l}\text { - Eliminar etapas des- } \\
\text { necessárias } \\
\text { - Introduzir etapas } \\
\text { - Adaptar interfaces }\end{array}$ \\
\hline & $\begin{array}{l}\text { Autorização da licitação e } \\
\text { elaboração do edital }\end{array}$ & $\begin{array}{l}\text { - As atividades } 15,18,19,22 \text { e } 23 \text { foram } \\
\text { eliminadas. }\end{array}$ & $\begin{array}{l}\text { - Eliminar etapas des- } \\
\text { necessárias }\end{array}$ \\
\hline & $\begin{array}{l}\text { Homologação e adjudica- } \\
\text { ção do vencedor }\end{array}$ & $\begin{array}{l}\text { - As atividades } 34,35,38 \text { e } 40 \text { foram eli- } \\
\text { minadas. } \\
\text { - As atividades "sobrestar processo origi- } \\
\text { nário" e "aguardar pedidos do setor" } \\
\text { passaram para a responsabilidade da } \\
\text { SECOMP. }\end{array}$ & $\begin{array}{l}\text { - Eliminar etapas des- } \\
\text { necessárias } \\
\text { - Adaptar interfaces }\end{array}$ \\
\hline \multirow{2}{*}{$\begin{array}{l}\text { Recebimento } \\
\text { do objeto lici- } \\
\text { tado }\end{array}$} & $\begin{array}{l}\text { Solicitação de recebi- } \\
\text { mento e empenho }\end{array}$ & $\begin{array}{l}\text { - As atividades } 48,49,51,52 \text { e } 55 \text { foram } \\
\text { eliminadas. }\end{array}$ & $\begin{array}{l}\text { - Eliminar etapas des- } \\
\text { necessárias }\end{array}$ \\
\hline & Pagamento & $\begin{array}{l}\text { - As atividades } 60,61,62 \text { e } 65 \text { foram eli- } \\
\text { minadas. }\end{array}$ & $\begin{array}{l}\text { - Eliminar etapas des- } \\
\text { necessárias }\end{array}$ \\
\hline
\end{tabular}

Fonte: Elaborado pelos autores.

Ao analisar o Quadro 3, observa-se que o procedimento de melhoria mais comum foi a eliminação de etapas desnecessárias. Essa constatação permite inferir duas causas principais. A primeira é que o excesso burocrático do Setor Público gera um alto volume de trabalho que simplesmente não precisa ser realizado, mesmo respeitando todos os limites impostos pela legislação vigente. A segunda causa potencial é que a eliminação de etapas desnecessárias representa o tipo de melhoria que fica mais evidente com a elaboração do mapa dom processo. As melhorias relacionadas à automatização ou à aceleração do processamento, por exemplo, demandariam uma análise mais aprofundada e uma modelagem mais completa do que a que foi realizada para o propósito deste trabalho.

A partir do mapeamento do macroprocesso pregão presencial com registro de preço e da análise do seu fluxo observa-se que este percorre um caminho demasiado longo pela excessiva e desnecessária concentração de atividades nas coordenadorias e secretarias superiores. Caminho 
traçado por designações regimentais e normativas obsoletas, que visam atender mais a conformidades hierárquicas do que a eficiência processual. A função das melhorias aqui apresentadas é diminuir o tempo de realização do processo de compra, porém, apesar de ser o tempo o elemento chave, não é possível mensurar com maior precisão o quanto se economizaria em dias ou horas com as propostas sugeridas, já que uma solicitação de compra pode contemplar apenas um ou cinquenta itens, por exemplo, implicando uma análise mais demorada da solicitação.

Apesar de a variação das solicitações de compra inviabilizar uma mensuração precisa do tempo economizado, é possível, como foi informado pelos servidores entrevistados, eliminar pontos de estanque sem prejudicar a qualidade e confiabilidade do processo, de forma que um processo que demanda atualmente no mínimo cinco meses para finalizar, poderia levar três meses se suprimidos os excessos burocráticos apontados pela análise do processo. O objetivo do pregão é licitar produtos de características simples com maior rapidez que as outras modalidades. Porém, a agilidade proposta pelo pregão se perde na tramitação interna que está fortemente arraigada em preceitos de disfunções burocráticas.

Cada macroprocesso de compra do TRE-PB é composto por etapas diferentes. Cada um tem suas particularidades, porém, todos seguem a mesma lógica burocrática. Desta forma, com as devidas adaptações, pode-se estender aos demais macroprocessos as propostas apresentadas neste estudo, já que têm como ponto central eliminar exageros da burocracia praticada.

A adoção das sugestões propostas exigiria adaptações no sistema gerencial do TRE-PB em diferentes perspectivas, como reajustar a prática gerencial para uma orientação por processos, realizar programas de treinamento e capacitação para atuação em processos mais enxutos, e usar a tecnologia da informação para aumentar a eficiência dos processos existentes.

\section{CONSIDERAÇÕES FINAIS}

A estrutura processual de aquisição de bens e serviços na Administração Pública é composta por elementos legais e obrigatórios que atendem aos princípios e finalidades que norteiam esta prática. Através do mapeamento de um processo de compra, pôde-se perceber claramente a estrutura verticalizada e burocrática em que a organização estudada se configura. É um exemplo típico de uma organização pública apegada excessivamente às normas e regimentos.

Está previsto na Constituição Brasileira, no artigo 37, outro princípio, além da moralidade e publicidade, que juntamente com os demais regem as organizações públicas: o princípio da eficiência. É com este olhar que se sugere ao TRE-PB uma nova abordagem para o processo de compra de bens na modalidade pregão, a fim de sanar a incoerência entre a prática e aquilo que o pregão se propõe. É necessária uma modernização gerencial na interação entre os setores e no desenvolvimento das atividades, focando na gestão por processos.

O que se condena não é a burocracia em si, mas os excessos burocráticos que camuflam o real sentido do processo estudado. E é neste ponto que surge o mapeamento do processo como uma ferramenta eficaz para enxergar com clareza as atividades primordiais para uma execução excelente, abandonando ou redefinindo as atividades dispensáveis ou inadequadas. Dessa forma, libertando-se de um viés vertical e rígido, o processo estudado deve traçar um caminho mais horizontal, pois é ilógico percorrer hierarquias que não executam ações efetivamente, eliminando atividades desnecessárias e interligando as essenciais numa perspectiva horizontal.

Através das melhorias aqui propostas, o TRE-PB poderia gerir com maior eficiência suas 
compras ao adotar um processo mais rápido e confiável, que proporcione com segurança a programação de estoques e previsão de compras. Ao adotar um processo que flua pela a organização sem estorvos, aumenta a qualidade dos serviços de suprimentos aos setores, garantindo as condições ideais para execução das suas atividades através do recebimento dos materiais no tempo adequado, por conseguinte, eleva o funcionamento da organização.

Entende-se que o objetivo deste estudo foi alcançado, ou seja, possibilidades de melhorias no processo de compras de bens na modalidade pregão presencial com registro de preço do TREPB foram identificadas. A principal dificuldade encontrada ocorreu na compreensão inicial das etapas que compõem o processo, pois se trata de um fluxo longo que envolve vários setores e atividades.

O término desse trabalho não resulta necessariamente no encerramento dessa discussão, podendo ser aprofundada em trabalhos futuros, seja na utilização de outras abordagens de meIhorias, seja na replicação em outras organizações do mesmo caráter.

\section{REFERÊNCIAS}

1. ABPMP (Association of Business Process Management Professionals). Guia para o gerenciamento de processos de negócio: corpo comum de conhecimento (BPM CBOK V3.0). [S.I.]: ABPMP, 2013.

2. ACEVEDO, C. R; NOHARA, J. J. Monografia no curso de Administração: guia completo de conteúdo e forma. São Paulo: Atlas, 2007.

3. ADESOLA, S.; BAINES, T. Developing and evaluating a methodology for business process improvement. Business Process Management Journal, v. 11, n. 1, p. 37-46, 2005.

4. AGUILAR-SAVÉN, R. S. Business process modelling: review and framework. International Journal of Production Economics, v. 90, n. 2, p. 129-149, 2004.

5. AITKEN, C.; STEPHENSON, C.; BRINKWORTH, R. Process classification frameworks. In: VOM BROCKE, J.; ROSEMANN, M. (Ed.). Handbook on Business Process Management. Heidelberg: Springer, 2010. v. 2, p. 73-92.

6. ARMISTEAD, C.; MACHIN, S. Implications of business process management for operations management. International Journal of Operations \& Production Management, v. 17, n. 9, p. 886-898, 1997.

7. BERGMAN, M. A.; LUNDBERG, S. Tender evaluation and supplier selection methods in public procurement. Journal of Purchasing and Supply Management, v. 19, n. 2, p. 73-83, 2013.

8. BRANDON, J.; MORRIS, D. Reengenharia: reestruturando sua empresa. São Paulo: Makron Books, 1994.

9. BRASIL. Tribunal Regional Eleitoral. Compras efetuadas. Disponível em: < http://www.justicaeleitoral.jus.br/arquivos/tre-pb-relatorio-de-compras-julho-2015>. Acesso em: 13 jan. 2016.

10. COSKUN, S.; BASLIGIL, H.; BARACLI, H. A weakness determination and analysis model for business process improvement. Business Process Management Journal, v. 14, n. 2, p. 243261, 2008.

11. DASSISTI, M. HY-CHANGE: a hybrid methodology for continuous performance improvement of 
manufacturing processes. International Journal of Production Research, v. 48, n. 15, p. 43974422, 2010.

12. DAVENPORT, T. H. Reengenharia de processos: como inovar na empresa através da tecnologia da informação. Rio de Janeiro: Campus, 1994.

13. DI PIETRO, M. S. Z. Direito administrativo. 21.ed. São Paulo: Atlas, 2008.

14. DIAS, M. A. P. Administração de materiais: princípios, conceitos e gestão. 6.ed. 5.reimpr. São Paulo: Atlas, 2011.

15. DONEL, A. J. et al. As vantagens do sistema registro de preço utilizando a modalidade pregão nas compras públicas: SAMAE de São Francisco do Sul. 2008. Disponível em: <http://www.administradores.com.br>. Acesso em: 03 nov. 2009.

16. EDQUIST, C.; ZABALA-ITURRIAGAGOITIA, J. M. Public procurement for innovation as missionoriented innovation policy. Research Policy, v. 41, n. 10, p. 1757-1769, 2012.

17. FERNANDES, C. C. C. Transformações na gestão de compras da administração pública brasileira. Disponível em: <http://unpan1.un.org/intradoc/groups/public/documents/CLAD/clad0047330.pdf>. Acesso em: 03 nov. 2009.

18. GARVIN, D. A. The processes of organization and management. Sloan Management Review, v. 39, n. 4, p. 33-50, 1998.

19. GASPARINI, D. Direito administrativo. 13.ed. São Paulo: Saraiva, 2008.

20. GULLEDGE JR., T. R.; SOMMER, R. A. Business process management: public sector implications. Business Process Management Journal, v. 8, n. 4, p. 364-376, 2002.

21. HAMMER, M. Além da reengenharia: como organizações orientadas para processos estão mudando nosso trabalho e nossas vidas. Rio de Janeiro: Campus, 1997.

22. HARRINGTON, H. J. Aperfeiçoando processos empresariais: estratégia revolucionária para o aperfeiçoamento da qualidade, da produtividade e da competitividade. São Paulo: Makron Books, 1993.

23. HUGHES, M.; SCOTT, M.; GOLDEN, W. The role of business process redesign in creating egovernment in Ireland. Business Process Management Journal, v. 12, n. 1, p. 76-87, 2006.

24. KHAN, Z.; BALI, R. K.; WICKRAMASINGHE, N. Developing a BPI framework and PAM for SMEs. Industrial Management \& Data Systems, v. 107, n. 3, p. 345-360, 2007.

25. LEE, K. T.; CHUAH, K. B. A SUPER methodology for business process improvement: an industrial case study in Hong Kong/China. International Journal of Operations \& Production Management, v. 21, n. 5/6, p. 687-706, 2001.

26. MACINTOSH, R. BPR: alive and well in the public sector. International Journal of Operations \& Production Management, v. 23, n. 3, p. 327-344, 2003.

27. MCADAM, R. An integrated business improvement methodology to refocus business improvement efforts. Business Process Re-engineering \& Management Journal, v. 2, n. 1, p. 63-71, 1996.

28. MEIRELLES, H. L. Direito administrativo brasileiro. 31.ed. São Paulo: Malheiros, 2005. 
29. MISCHAK, R. F. Business reengineering - der weg vom funktions- zum prozeßorientierten denken im unternehmen. In: BERNDT, R. (Ed.). Business reengineering: effizientes neugestalten von geschäftsprozessen. Berlin: Springer, 1997. p. 3-17.

30. PAIM, R. et al. Gestão de processos: pensar, agir e aprender. Porto Alegre: Bookman, 2009.

31. PALMA-MENDOZA, J. A.; NEAILEY, K.; ROY, R. Business process re-design methodology to support supply chain integration. International Journal of Information Management, v. 34, n. 2, p. 167-176, 2014.

32. PIDD, M. Tools for thinking: modelling in Management Science. 2.ed. Chichester, UK: Wiley, 2003.

33. POVEY, B. The development of a best practice business process improvement methodology. Benchmarking for Quality Management \& Technology, v. 5, n. 1, p. 27-44, 1998.

34. ROHLEDER, T. R.; SILVER, E. A. A tutorial on business process improvement. Journal of Operations Management, v. 15, n. 2, p. 139-154, 1997.

35. ROTHER, M.; SHOOK, J. Aprendendo a enxergar: mapeando o fluxo de valor para agregarvalor e eliminar o desperdício. São Paulo: Lean Institute Brasil, 2003.

36. SAMPIERI, R. H.; COLLADO, C. F.; LUCIO, M. P. B. Metodologia de pesquisa. 5.ed. Porto Alegre: Penso, 2013.

37. SCHROEDER, R. G. et al. Six sigma: definition and underlying theory. Journal of Operations Management, v. 26, n. 4, p. 536-554, 2008.

38. SIHA, S. M.; SAAD, G. H. Business process improvement: empirical assessment and extensions. Business Process Management Journal, v. 14, n. 6, p. 778-802, 2008.

39. TADELIS, S. Public procurement design: lessons from the private sector. International Journal of Industrial Organization, v. 30, n. 3, p. 297-302, 2012.

40. VERGARA, S. C. Projetos e relatórios de pesquisa em Administração. São Paulo: Atlas, 2008.

41. VIANA, J. J. Administração de materiais: um enfoque prático. São Paulo: Atlas, 2000.

42. WAAL, B. M. E.; BATENBURG, R. The process and structure of user participation: a BPM system implementation case study. Business Process Management Journal, v. 20, n. 1, p. 107-128, 2014.

43. YIN, R. K. Estudo de caso: planejamento e métodos. 5.ed. Porto Alegre: Bookman, 2015.

44. ZWICKER, J.; FETTKE, P.; LOOS, P. Business process maturity in public administrations. In: VOM BROCKE, J.; ROSEMANN, M. (Ed.). Handbook on Business Process Management. Heidelberg: Springer, 2010. v. 2, p. 369-396. 